\title{
Thermodynamics Analysis on Carbon Reducing of Coal Fly Ash to Si-Al Alloy
}

\author{
Zhiling Bai 1,a, Bingke Qin ${ }^{1,2, b}$, Minglei Lian ${ }^{1, c}$, Yingju Miao ${ }^{1,3, d}$
}

\author{
${ }^{1}$ School of Chemistry and Materials Engineering, Liupanshui Normal University, Liupanshui,China \\ ${ }^{2}$ College of Materials and Metallurgy, Guizhou University, Guiyang, China \\ ${ }^{3}$ School of Chemical Engineering,Kunming University of Science and Technology, Kunming,China

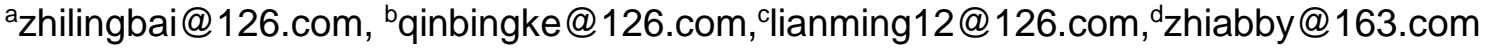

\begin{abstract}
Keywords: coal fly ash; Si-Al alloy; HSC chemistry; thermodynamics
Abstract. The thermodynamics of the reactions for carbon reducing of coal fly ash to Si-Al alloy were investigated with HSC Chemistry 6.0 thermodynamic analysis software.The standard molar enthalpy change, Gibbs free energy and equilibrium constant of the reaction system at different temperatures were calculated. The relationship between the thermodynamic parameters and the temperature were analyzed.The results showed that the rapid increasing of the reaction temperature and avoiding residence time of reactants in low temperature were conducive for the formation of $\mathrm{Si}-\mathrm{Al}$ alloy. The results provided a theoretical basis and basic data for the preparation of Si-Al alloy with carbon reduction coal fly ash.
\end{abstract}

\section{Introduction}

Si-Al alloy has many merits such as light and tough, good casting performance, with good mechanical strength, corrosion resistance and low alloy melting point.Si-Al alloy is generally used in transportation, medical equipment, equipment parts and other fields[1,2].In addition, the reduction of $\mathrm{Si}-\mathrm{Al}$ alloy is strong at high temperature. If $\mathrm{Si}-\mathrm{Al}$ alloy is used as a deoxidizer during smelting, it can reduce the subcutaneous bubble sensitivity of the steel, thereby enhancing the quality of the steel. China has two kinds of $\mathrm{Si}-\mathrm{Al}$ alloy production methods: one is blending method; the other is the use of high-grade bauxite smelting $\mathrm{Si}$-Al alloy, but these two methods of production of $\mathrm{Si}-\mathrm{Al}$ alloy cost is relatively high, leading to high prices of $\mathrm{Si}-\mathrm{Al}$ alloy[3].

Coal fly ash is a kind of industrial solid waste, the current comprehensive utilization of coal fly ash, mainly for brick, backfill, bedding road, sorting floating beads, the production of cement and so on, but the utilization rate is low. Through the laboratory analysis, many coal fly ash contains a lot of $\mathrm{Al}_{2} \mathrm{O}_{3}$ and $\mathrm{SiO}_{2}$, if the use of coal fly ash extraction of Si-Al alloy that is undoubtedly a new way to control the pollution of coal fly ash and improve the environment[4].The metallurgical industry has opened up a new source of Si-Al alloy.In this study, HSC Chemistry 6.0 thermodynamics software was used to analyze the possible reaction of $\mathrm{Si}$ - $\mathrm{Al}$ alloy prepared by carbon reduction coal fly ash. The relationship between Gibbs free energy, the standard molar enthalpy change,the equilibrium constant and temperature were investigated. It is helpful to further study the mechanism of the preparation of $\mathrm{Si}-\mathrm{Al}$ alloy by carbothermal reduction and improve the comprehensive utilization rate of coal fly ash.The preparation of $\mathrm{Si}-\mathrm{Al}$ alloy by high frequency induction furnace also has a certain guiding significance.

\section{Research methods}

HSC Chemistry is the world's most widely used thermodynamics software developed by the Outokumpu Research Center in Finland and has a database of more than 20,000 inorganic thermo-mechanical properties. Using HSC Chemistry 6. 0 in the Reaction Equation module to carry out the reaction balance thermodynamics calculation[5]. The module is based on the principle of Gibbs free energy minimum principle and entropy increase. In response to the possible reactions of the system, calculate the Gibbs free energy of the reactions using HSC Chemistry 6.0 software with the temperature change.By comparing the trend of $\Delta \mathrm{G}$ of each reaction, the relative difficulty of 
each reaction was obtained.The standard molar enthalpy change of each reaction was compared to obtain the optimum reaction temperature. The equilibrium constant of each reaction was investigated and the degree of spontaneous reaction of each reaction was obtained.

There is no unified view of the mechanism of the preparation of trend alloy by carbothermal reduction of coal fly ash. The possible reactions include[6]:

$$
\begin{aligned}
& 2 \mathrm{Al}_{2} \mathrm{CO}+3 \mathrm{C}=\mathrm{Al}_{4} \mathrm{C}_{3}+2 \mathrm{CO}(\mathrm{g}) \\
& 2 \mathrm{Al}_{2} \mathrm{O}_{3}+3 \mathrm{C}=\mathrm{Al}_{4} \mathrm{O}_{4} \mathrm{C}+2 \mathrm{CO}(\mathrm{g}) . \\
& 2 \mathrm{Al}_{2} \mathrm{O}_{3}+9 \mathrm{C}=\mathrm{Al}_{4} \mathrm{C}_{3}+6 \mathrm{CO}(\mathrm{g}) . \\
& \mathrm{Al}_{2} \mathrm{O}_{3}+3 \mathrm{C}=2 \mathrm{Al}+3 \mathrm{CO}(\mathrm{g}) . \\
& \mathrm{Al}_{2} \mathrm{O}_{3}+3 \mathrm{C}=\mathrm{Al}_{2} \mathrm{CO}+2 \mathrm{CO}(\mathrm{g}) . \\
& \mathrm{Al}_{2} \mathrm{O}_{3}+\mathrm{Al}_{4} \mathrm{C}_{3}=6 \mathrm{Al}+3 \mathrm{CO}(\mathrm{g}) . \\
& \mathrm{Al}_{4} \mathrm{O}_{4} \mathrm{C}+6 \mathrm{C}=\mathrm{Al}{ }_{4} \mathrm{C}+4 \mathrm{CO}(\mathrm{g}) . \\
& \mathrm{SiO}_{3}+2 \mathrm{C}=\mathrm{SiC}+\mathrm{CO}(\mathrm{g}) . \\
& \mathrm{SiO}_{2}+2 \mathrm{C}=\mathrm{Si}+2 \mathrm{CO}(\mathrm{g}) . \\
& \mathrm{SiO}_{2}+2 \mathrm{SiC}=3 \mathrm{Si}+2 \mathrm{CO}(\mathrm{g}) . \\
& \mathrm{SiO}_{2}+3 \mathrm{C}=\mathrm{SiC}+2 \mathrm{CO}(\mathrm{g}) . \\
& \mathrm{SiO}_{2}+\mathrm{C}=\mathrm{SiO}+\mathrm{CO}(\mathrm{g}) . \\
& \mathrm{SiO}_{2}+2 \mathrm{Si}=2 \mathrm{SiO} . \\
& 3 \mathrm{SiO}_{2}+2 \mathrm{Al}{ }_{4} \mathrm{C}_{3}=8 \mathrm{Al}+3 \mathrm{Si}+6 \mathrm{CO}(\mathrm{g}) .
\end{aligned}
$$

\section{Results and discussion}

\section{Relationship between $\Delta \mathrm{G}$ and temperature for the reactions.}

The Gibbs free energy change $(\Delta \mathrm{G})$ of the reactions R-(1) R-(14) can be calculated using the reaction equations module of HSC Chemistry 6. 0[7].Relationship between $\Delta \mathrm{G}$ and temperature for reactions R-(1) R-(14) are shown in Fig.1.According to the thermodynamic criterion, the criterion of whether a reaction can be spontaneous is Gibbs free energy less than zero[8], the more negative the reaction is, the more easily it is carried out. It can be seen from Fig.1(b), the Gibbs free energy of the reaction $\mathrm{R}-(8)$ in the temperature range are greater than zero, it can not be carried out spontaneously.The starting temperature of R-(1),R-(2), R-(3) and R-(5) were 2304K, 2118K, 2273K, $2229 \mathrm{~K}$, respectively; the initial temperature of R-(4), R-(6), R-(9), R-(10) and R-(14) were 2308K, $2376 \mathrm{~K}, 1939 \mathrm{~K}, 2154 \mathrm{~K}, 2059 \mathrm{~K}$, respectively.It can be seen that the thermodynamic condition of aluminum carbide is better than that of aluminum. The starting temperature of reaction R-(9) is $1939 \mathrm{~K}$, the initial temperature of reaction R-(11) is $1814 \mathrm{~K}$, and the formation temperature of silicon carbide is lower than that of silicon. Accordingly, the system should rapidly heat up to the formation temperature of aluminum, reduce the residence time at low temperature, and improve the yield of Si-Al alloy. 

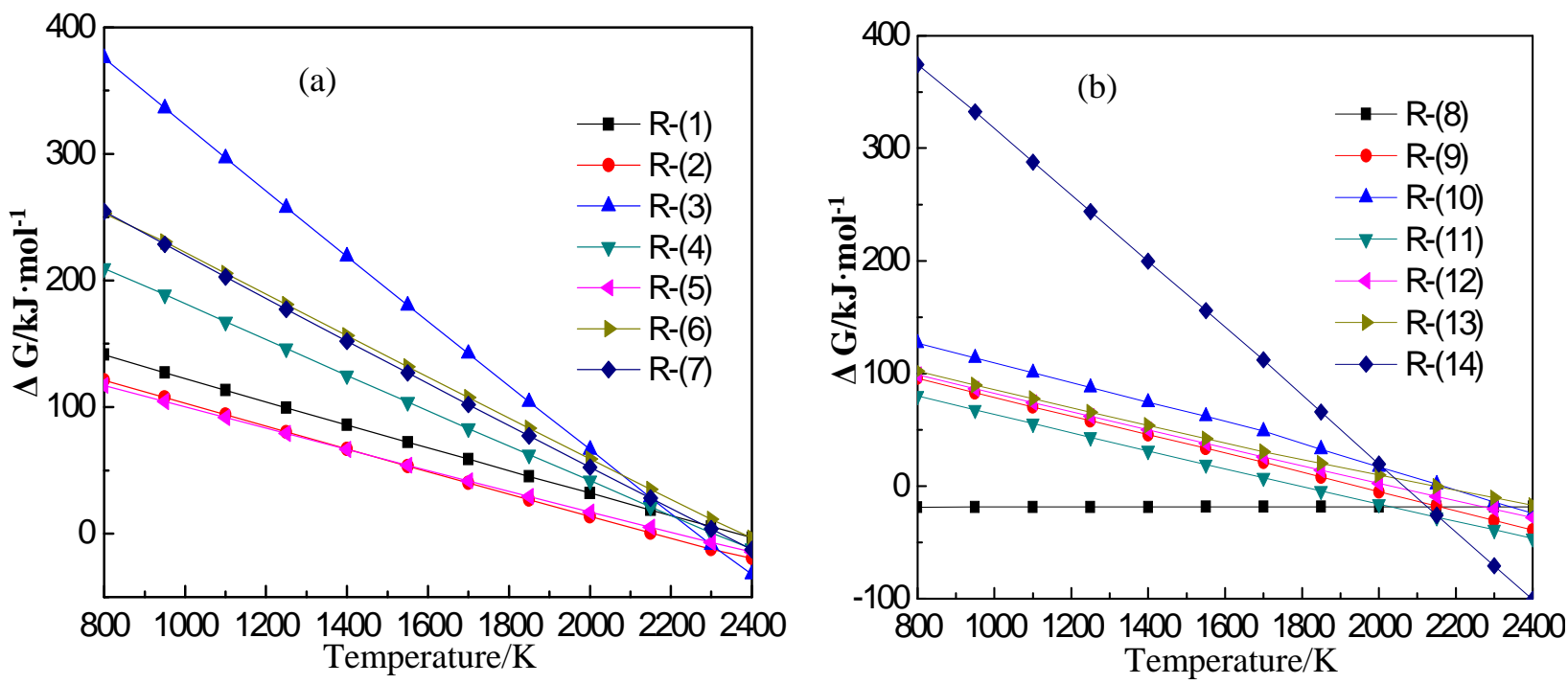

Fig.1 Relationship between $\Delta \mathrm{G}$ and temperature for reactions

(a) R-(1) R-(7); (b) R-(8) R-(14)

\section{Relationship between $\operatorname{logK}$ and temperature for the reactions.}

Relationship between $\log \mathrm{K}$ and temperature for the reactions can be seen from Fig.2.The spontaneous reaction of $\mathrm{R}-(1) \sim \mathrm{R}-(14)$ are weak in the low temperature stage.The equilibrium constant of $\mathrm{R}-(8)$ with temperature changes little, while equilibrium constant of R-(1) R-(7), R-(9) R-(14) reaction gradually become larger with temperature changed. R-(4), R-(6), R-(9), R(10), R-(14) are the desired reaction. Increasing reaction temperature is beneficial to the production of Si-Al Alloy.
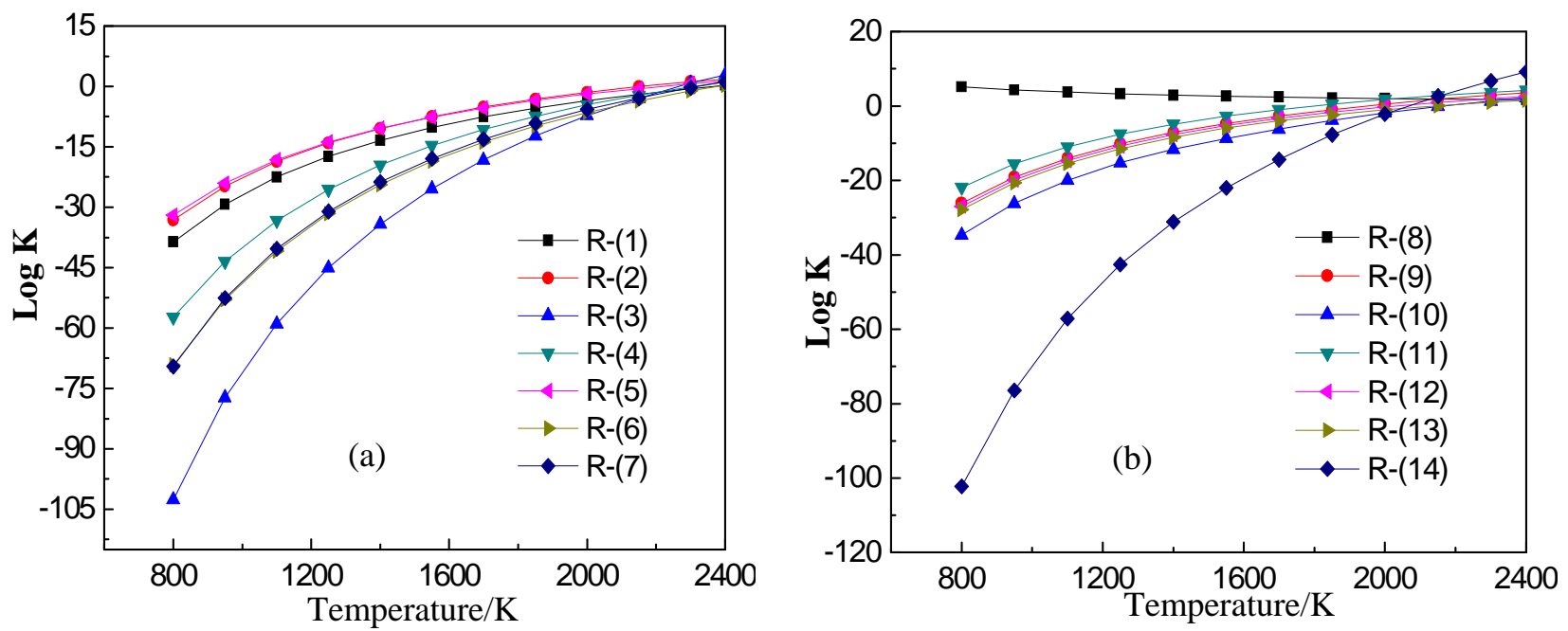

Fig.2 Relationship between $\log \mathrm{K}$ and temperature for reactions

(a) R-(1) R-(7); (b) R-(8) R-(14)

\section{Relationship between $\Delta \mathrm{H}$ and temperature for the reactions.}

Relationship between $\Delta \mathrm{H}$ and temperature for reactions $\mathrm{R}-(1) \sim \mathrm{R}-(14)$ are given in Fig.3.The reaction enthalpy the of $\mathrm{R}-(1) \sim \mathrm{R}-(7), \mathrm{R}-(9) \sim \mathrm{R}-(14)$ are greater than zero, reactions $\mathrm{R}-(1) \sim \mathrm{R}-$ (7), R-(9) R-(14) are the endothermic reaction,increasing temperature is favourable to R-(1) R(7),R-(9) R-(14).R-(8) is the exothermic reaction, and it is favorable at low temperature. According to the above analysis, it can be considered that $\mathrm{R}-(1) \sim \mathrm{R}-(14)$ reaction can occur, but the reaction is affected by the temperature, and the degree of difficulty of reactions are different. Keeping the reaction temperature between $1900 \sim 2300 \mathrm{~K}$ is the most favorable for the system. 

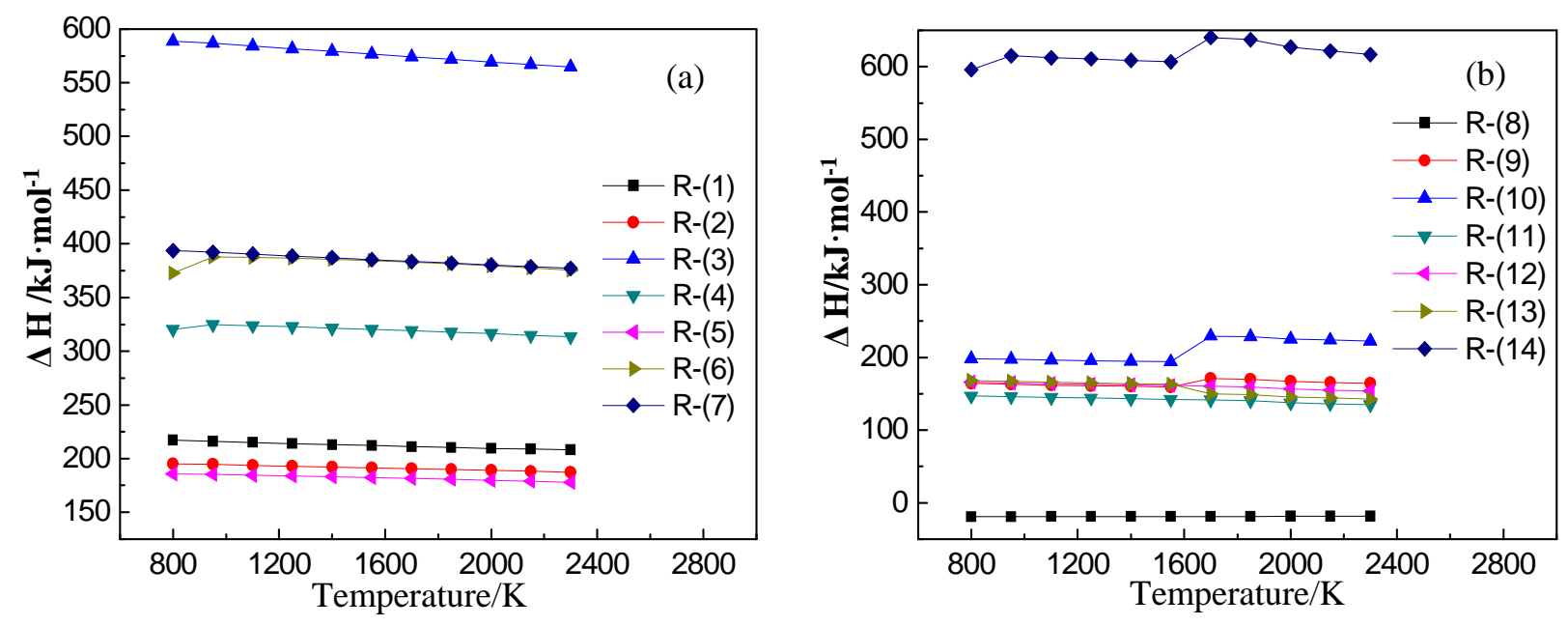

Fig.3 Relationship between $\Delta \mathrm{H}$ and temperature for reactions

(a) R-(1) R-(7); (b) R-(8) R-(14)

\section{Conclusions}

The thermodynamic condition of aluminum carbide is better than that of aluminum,and the formation temperature of silicon carbide is lower than that of silicon. Accordingly, the system should rapidly heat up to the formation temperature of aluminum, reduce the residence time at low temperature, and improve the yield of $\mathrm{Si}-\mathrm{Al}$ alloy.The results of relationship between $\log \mathrm{K}$ and temperature for the reactions indicates that increasing reaction temperature is beneficial to the production of Si-Al Alloy.

Relationship between $\Delta \mathrm{H}$ and temperature for reactions shows that R-(1) R-(14) reaction can be occurred, but the reaction is affected by the temperature, and the degree of difficulty of reactions are different. Keeping the reaction temperature between $1900 \sim 2300 \mathrm{~K}$ is the most favorable for the system.

\section{Acknowledgments}

This work was financially supported by the Guizhou Provincial Science and Technology Foundation (No.[2014]7460),Solid Waste Recycling Laboratory of Coal Utilization(No.2011-278), the Liupanshui Normal University High-Level Talent Research Start Foundation (LPSSYKYJJ201 417), and Guizhou province ordinary college innovation team of mineral processing and comprehensive utilization of scientific and technological (No.[2015] 69).

\section{References}

[1]D.K.Ward,W.A.Curtin,YueQi.Comp. Sci. Technol.Vol.66(2006),p.1151-1161.

[2]Y.L.Saraswathi,S.Das,D.P.Mondal.Mater.Sci.Eng A.Vol.3(2006),p.11-21.

[3]Keqiang Xie, Ziliang Liu, Wenhui Ma, et al. J. Kunming Uni.Sci. Techno.(Natural Science Edition).Vol.40(2015),p.1-7. In Chinese

[4]Ziyong Li,Chunhan Wu,Qingchun Yu,et al.J.Chin. Coal Soc.Vol.41(2016),p.769-775. In Chinese [5]PICKLES C A. J. Hazard. Mater.Vol.179(2010),p.309-317.

[6]J.M.Lihrmann.J. Eur. Ceram. Soc. Vol.28(2008),p.633-642.

[7]FENG B, BHATIA S K. Chem.Eng. Sci.Vol.57(2002),p.2907-2920.

[8]Ziyong Li,Chunhan Wu,Qingchun Yu,et al.Chin. J.Eng.Vol.38(2016),p.834-840. In Chinese 